Article

\title{
A Holistic Approach to Integrate and Evaluate Sustainable Development in Higher Education. The Case Study of the University of the Basque Country
}

\author{
Estibaliz Sáez de Cámara *, Idoia Fernández (D) and Nekane Castillo-Eguskitza (D) \\ Vice-Rectorate of Innovation, Social Commitment and Cultural Action of the University of the Basque \\ Country (UPV/EHU), Leioa, 48940 Bizkaia, Spain; idoia.fernandez@ehu.eus (I.F.); \\ nekane.castillo@ehu.eus (N.C.-E.) \\ * Correspondence: estibaliz.saezdecamara@ehu.eus
}

\section{Citation: Sáez de Cámara, E.;}

Fernández, I.; Castillo-Eguskitza, N.

A Holistic Approach to Integrate and Evaluate Sustainable Development in Higher Education. The Case Study of the University of the Basque Country. Sustainability 2021, 13, 392.

https://doi.org/10.3390/su13010392

Received: 16 October 2020 Accepted: 29 December 2020 Published: 4 January 2021

Publisher's Note: MDPI stays neutral with regard to jurisdictional clai$\mathrm{ms}$ in published maps and institutional affiliations.

Copyright: () 2021 by the authors. Licensee MDPI, Basel, Switzerland. This article is an open access article distributed under the terms and conditions of the Creative Commons Attribution (CC BY) license (https:// creativecommons.org/licenses/by/ $4.0 /)$.

\begin{abstract}
Since the United Nations (UN) approved the Agenda 2030 for Sustainable Development in 2015, higher education institutions have increasingly demonstrated their commitment by supporting several initiatives. Although a great deal of progress has been made, there is still a lack of integrative approaches to truly implement Sustainable Development Goals (SDGs) in higher education. This paper presents a practical case that illustrates how to design and articulate SDGs within an institutional setting adopting a holistic approach: EHUagenda 2030 plan of the University of the Basque Country (UPV / EHU). It is based on empirical inquiry into global and holistic sustainable transformation and a real experience to move towards a verifiable and pragmatic contribution to sustainability. This plan describes the contribution to 12 of the 17 SDGs, along with three sectorial plans (Equality Campus, Inclusion Campus and Planet Campus), as well as the refocus of the UPV/EHU's Educational Model and the panel of sustainable development indicators, which addresses the technical aspects of monitoring the SDGs. The methodology (mapping; mainstreaming; diagnosis and definition and, finally, estimation) is systematic and replicable in other universities yet to embark upon this integration. This case study makes a contribution towards the understanding of the complexity of the changes in Higher Education and the ways to approach it.
\end{abstract}

Keywords: sustainable development goals; university; institutional policy; learning strategy; indicators

\section{Introduction: The United Nations (UN) 2030 Agenda for Sustainable Development and Higher Education}

Continuing the work started in 2000 with the Millennium Development Goals (MDGs), in 2015, the 2030 Agenda for Sustainable Development was adopted by 193 countries at the United Nations General Assembly [1]. The 2030 Agenda is recognized as transformative, universal and integrated and provides a shared blueprint for peace and prosperity for people and the planet, now and into the future. It is focused on the whole world, i.e., developed and developing countries, so that all nation states embrace the responsibility of applying this new agenda and pledge to ensure that "no one will be left behind".

The 2030 Agenda comprises 17 Sustainable Development Goals (SDGs), 169 targets and 232 monitoring indicators focused on economic, social and environmental issues. SDGs define global sustainable development priorities and seek to mobilize global efforts around a common set of goals and targets in a global partnership for the year 2030. They recognize that ending poverty and other deprivation must go hand-in-hand with strategies that improve health and education, reduce inequality, and spur economic growth, while tackling climate change and working to preserve our oceans and forests.

This agenda is an urgent call for worldwide action and its success relies on action and collaboration by all actors, including not only governments, but also businesses, civil society and organizations, without forgetting universities. The SDG framework has a 
specific goal regarding Education (SDG4-Ensure inclusive and quality education for all and promote lifelong learning); and, for the first time, an international agenda makes explicit reference to Higher Education. Target 4.3 of SDG4 refers specifically to higher education by demanding equal access for all women and men to affordable and quality technical, vocational and tertiary education, "including university". Higher Education was never explicitly involved in the MDGs, either as a development goal in its own right nor as a potential agent to address other development goals [2].

\subsection{Call for Action by Universities and an Opportunity for Universities}

Addressing SDGs requires societies to be transformed into pathways of sustainable development and changes in the way humans interact with the planet. Universities, whose mission is to create and disseminate knowledge, have a vital role to play in addressing the planet's greatest challenges and achieving the SDGs [3]. Education, research, innovation and leadership will be essential in helping society to transform and address these challenges.

There is no doubt that the SDGs will barely be achieved without universities. "None of the 17 Sustainable Development Goals can be achieved without the contribution of higher education and research". That was the key message of a statement launched by the Association of Commonwealth Universities, the Agence Universitaire de la Francophonie and the International Association of Universities at the UN High-level Political Forum on Sustainable Development held in New York last year [4].

According to the Sustainable Development Solutions Network (SDSN) guide entitled "Getting Started with the SDGs in Universities", the most complete and concise documents on the topic published so far, there are four main areas where universities can contribute to the SDGs: learning and teaching, research, governance, culture and operations of the university and, external leadership [3]. First of all, education needs to be meaningful and address sustainable development; universities can include sustainable development within their curricula and methodologies, foster necessary capabilities and skills, promote humanistic values, evaluate students in sustainability, develop courses aimed at teaching global awareness, and include online and lifelong learning opportunities $[5,6]$. Secondly, universities must include the concept of responsible research and innovation in all their research activities, support research on topics that address the SDGs, support social entrepreneurs, and support capacity building and science for and with society [7]. Thirdly, university governance structures should be in line with the principles of sustainable development [8,9], and all actions within the university should be directed towards the sustainable goals, including smart campuses, women's empowerment, innovative methodologies and awareness-raising of human rights campaigns. Finally, universities should advocate for sustainable development, provide opportunities for inter-stakeholder dialogues and actions [10], as well as developing joint courses and programmes or research groups with other institutions on topics related to sustainable development and the promotion of capacity building.

Universities can contribute to the SDGs and, at the same time, universities can draw a range of benefits from the 2030 Agenda and by engaging with the SDGs [3]. Universities benefit themselves because they can demonstrate impact, capture more demand for SDG-related education, build new partnerships, access new funding streams, and make comparisons with other institutions, among others. Furthermore, the 2030 Agenda is an opportunity for universities to rethink the role of higher education institutions and shed light on the convenience of embedding certain values and practices in their mission and core values from a holistic approach.

In view of that, some universities, including Spanish ones, have already started to implement and include the concept of sustainability within their curricula, governing bodies, strategies and campuses management plans [11,12]. A number of networks related to sustainable development have been created or promoted within existing networks: SDSN, Higher Education and Research for Sustainable Development (HESD), International Sustainable Campus Network (ISCN), Association for the Advanced Sustainability in 
Higher Education (AASHE), University Educators for Sustainable Development (UE4SD), Sustainability and Education Policy Network (SEPN), Global Higher Education for Sustainability Partnership (GHESP) and University Leaders for a Sustainable Future (ULSF), among others. Relevant reports have been published, particularly the aforementioned SDSN Guide [3]. Several networks have started to compile good practices and cases from universities to show and serve as examples for other universities on how they can take action on the matter: ISCN [13] and Red Española para el Desarrollo Sostenible (REDS) [12]. Sustainability assessment tools, indicators and rankings have been proposed and tested, such as the Universitas Indonesia (UI) Green Metric World University Ranking on Sustainability [14] or the Word Impact Ranking for SDGs [15]. Specific journals such as the International Journal on Sustainability in Higher Education have been created (2015) and, a large number of universities have signed international agreements and conventions, such as the Halifax Declaration, Talloires Declaration, Copernicus Charter for Sustainable Development and the Salamanca Declaration.

All these efforts resulted in a significant increase in initiatives, projects, programs and dissemination activities related to sustainability in universities worldwide. The investigation also reports the results of these efforts. A detailed examination of 229 peer-reviewed research studies in the 2005-2018 time period selected from 44 journals in a recent study by Menon and Suresh [16] indicated that the implementation of sustainable development has been limited to its integration into teaching and learning and other aspects of educational practices. This examination demonstrated that only a few universities have been successful in implementing it holistically, that is, integrating all the triple bottom line dimensions in balance. Correlatively, the strategies for defining indicators, monitoring and measuring effectiveness have been oriented towards education for sustainable development (EfSD) $[17,18]$. Therefore, there is a widespread agreement on the findings of Leal Filho et al. [19]. They argue that, even though many universities have started to lead the way with different initiatives, many of those efforts address only one or two of the sustainability domains at universities, which continue to foster compartmentalization, instead of a holistic approach. Practical integration of sustainable development goals remains difficult [19-21]. Thus, present understanding of effective methods for integrating the 2030 agenda from a holistic approach is still limited.

Results from previous studies also pointed out some of the obstacles that impede the development of a holistic approach to the development of SDGs in universities. They suggest that the main ones are the lack of leadership from senior management for the promotion of policies and programs, the lack of ad hoc structures supporting these policies and, lastly, the absence of specific funding and resources [19]. In spite of this, there are more and more experiences emerging from universities that are undertaking transformation projects that broaden their focus from the purely pedagogical to engage in more comprehensive dynamics. At the same time, several cases have been published in different countries illustrating and contributing to this area with new knowledge on how to bring the alignment of the universities to the SDGs as an integrated and complex whole. Shiel, et al. [22] presented the case study from Bournemouth University in the United Kingdom. Filho et al. [23] carried out a comparative study of five universities in South Africa, Nigeria, United States, Brazil and Germany. They agree on the identified difficulties and conclude that the development of sustainability plans (particularly when combined with local and community development) could also act as an enabler to capacitybuilding, with a special attention to relevant matters of local and global interest. From all these qualitative case studies, the most relevant are those developed at the University of South Africa [24], the University of Bologna [25] and the Royal Melbourne Institute of Technology [26]. These three case studies not only report the institutional processes they carried out (leadership, set-up of priorities, plurality of topics, courses and programs on offer, engaging various stakeholders) but also detail their own systems of indicators for the monitoring of achievements. 
Our study makes a new contribution in this line since it documents a real case of the development of the SDGs from an integrated and global perspective and, at the same time presents a concrete methodology for the definition and measurement of the indicators that the University of the Basque Country built to control its own process. This paper puts forward the method applied, its difficulties and findings.

The conclusions presented here may be relevant for other higher education institutions. The most effective methodologies to integrate SDGs in universities have not been examined in detail. Current knowledge is limited to local and particular experiences. In an emerging field in which there are hardly any developed experiences and much less systematically documented and analyzed, the publication of well-structured case studies constitutes the first basis for validating more contrasted and robust knowledge.

\subsection{The Case Study: The University of the Basque Country}

The University of the Basque Country (UPV/EHU) is a public research university, deeply rooted in Basque society, open to the world, with an intellectual leadership and an ethical and social commitment. Its mission is to nurture an enlightened population by providing quality education and training based on knowledge, innovation and equity.

With a total of 20 schools and faculties distributed over three campuses (Araba, Bizkaia and Gipuzkoa), the UPV/EHU offers a wide range of degrees in all knowledge areas: from experimental sciences, engineering and humanities to health sciences, economics, fine arts and architecture.

The UPV /EHU offers 70 undergraduate programmes and 200 postgraduate programmes. All of them are fully adapted to the European Higher Education System (EEES). PhD studies lead to more than 400 graduates being granted their doctorate degrees every year.

It has a total undergraduate and postgraduate enrolment of 44,000 students, more than 3300 teaching staff, an administrative staff of 1500 persons and its annual budget is around 500 million euros. As a public institution, it is community-funded, and both fees and services rely on students only to a small extent. In keeping with its motto "Give and spread knowledge", the UPV/EHU is owned by all and open to all.

In 2010, the University was recognised as an "International Campus of Excellence" by the Spanish Ministry of Education and in 2014, it signed a partnership agreement with the University of Bordeaux to create a cross-border campus of international excellence, the first of its kind in Europe.

In recent years, the University of the Basque Country has significantly increased its scientific output in terms of international visibility in all areas of knowledge.

\subsection{Rethinking the Institutional Commitment to Sustainable Development}

Common to many other organizations, the UPV/EHU considers the 2030 Agenda and the SDGs as a model or framework that can accommodate the high quantity of the programmes implemented in recent years. In this area, certain degrees and research, promoting a human rights culture, gender equality policies, university development cooperation, environmental management or joint projects alongside organizations operating in the third sector showed that SDGs were not unrelated to who we were or what we did when the UN initiated this agenda in 2015.

Stopping there, however, would not be enough. Turning the SDGs into a strategy to validate what was already being done cannot be an option for organizations and it was not an option for the UPV/EHU [27]. The strategic plan of the university (2018-2021) included this mandate and the Vice-Rector's Office for Innovation, Social Commitment and Cultural Action was commissioned to carry it out with the explicit support of the Directorate for Sustainability.

The UPV / EHU consequently embarked on a process of rumination to define a strategy to bring the work of the University into line with the largest, most serious challenges facing the planet and to move towards making a verifiable, pragmatic contribution. The objectives/goals/aims of this process and the strategy were to: 
- Consistently incorporate the specific local efforts of students, teaching staff, researchers and technical and administrative staff regarding the SDGs, and take up the agenda as a common interconnected task to become part of all the university's activities.

- Create and apply policies for teaching-learning, equality, integration and environmental management by means of a common integrated logic with targets that are recognizable and measurable in the medium/long term.

- Set up a UPV/EHU Sustainable Development indicator panel, in this way achievements may be measured, monitored and communicated transparently.

- Develop a policy of close-knit partnerships with the environment to step up coresponsibility with the SDGs.

To carry out this task, a working group was created with external technical support from the Public Society for Environmental Management of the Basque Government (IHOBE). A participatory strategic reflection process was established, attended by seven people with management responsibilities at the university (senior managers) and three people belonging to the Basque Government and staff from IHOBE. Four intensive and participatory sessions were celebrated, and later, technical analysis and performing work. The result of this process was the EHUagenda 2030 for Sustainable Development (2019-2025) and its panel of indicators [28,29].

The following sections of this paper detail the methodology and result of this process of strategic reflection, planning and operationalization of the SDGs in a university. Guided and systematized reflection cycles were established in working papers that were progressively validated. This document takes a case study approach based on empirical research carried out by the authors who take part directly in the process of participative construction. Three main sources of information were used: (a) an analysis of professional and scientific literature on sustainable development in higher education; (b) the systematic analysis of the university's strategic documents in different areas (research, teaching and learning, equality, inclusion, development of the Basque language and environmental management) and, (c) reflection and analysis by the authors. Both the resulting educational model, as well as the sectoral plans, and the indicators were discussed and agreed in turn with the services and departments directly involved in the integration of the 2030 Agenda.

The case study that we present in this paper is a reconstruction of the methodological process. It aims to provide tangible and understandable operational keys that could be applied to other contexts. The results, discussion and conclusions presented here may be useful for the higher education institutions that are planning to integrate the 2030 Agenda, as well as for some other organizations.

\section{Methodology, Progressive Results and Discussion}

The main challenge is clearly to address the 2030 Agenda from a comprehensive and holistic approach: connecting multilevel agents and apparently independent issues requires new mindsets and new work methods.

The initial question at the start of this process was, therefore, "How can we deal with it?" In order to answer this first and critical query, we held several work sessions with a reflection group and we somewhat set the working methodology to define our 2030 Agenda. These were the methodological steps taken: (1) mapping, (2) mainstreaming, (3) diagnosis and definition of indicators and, (4) estimation of the indicators. They are represented in Figure 1.

\subsection{Mapping}

The first thing we did was to establish the starting point. We mapped the activities that were already contributing towards sustainable development (based on reports) and what we were planning to do (based on strategies and plans) in order to answer to the question "What is our situation?". Mapping specific efforts of the university community (students, teaching staff, researchers and technical and administrative staff) regarding the 
SDGs allowed us to establish the UPV /EHU starting point and draw up a route towards a verifiable and pragmatic contribution to the SDGs and the 2030 Agenda.

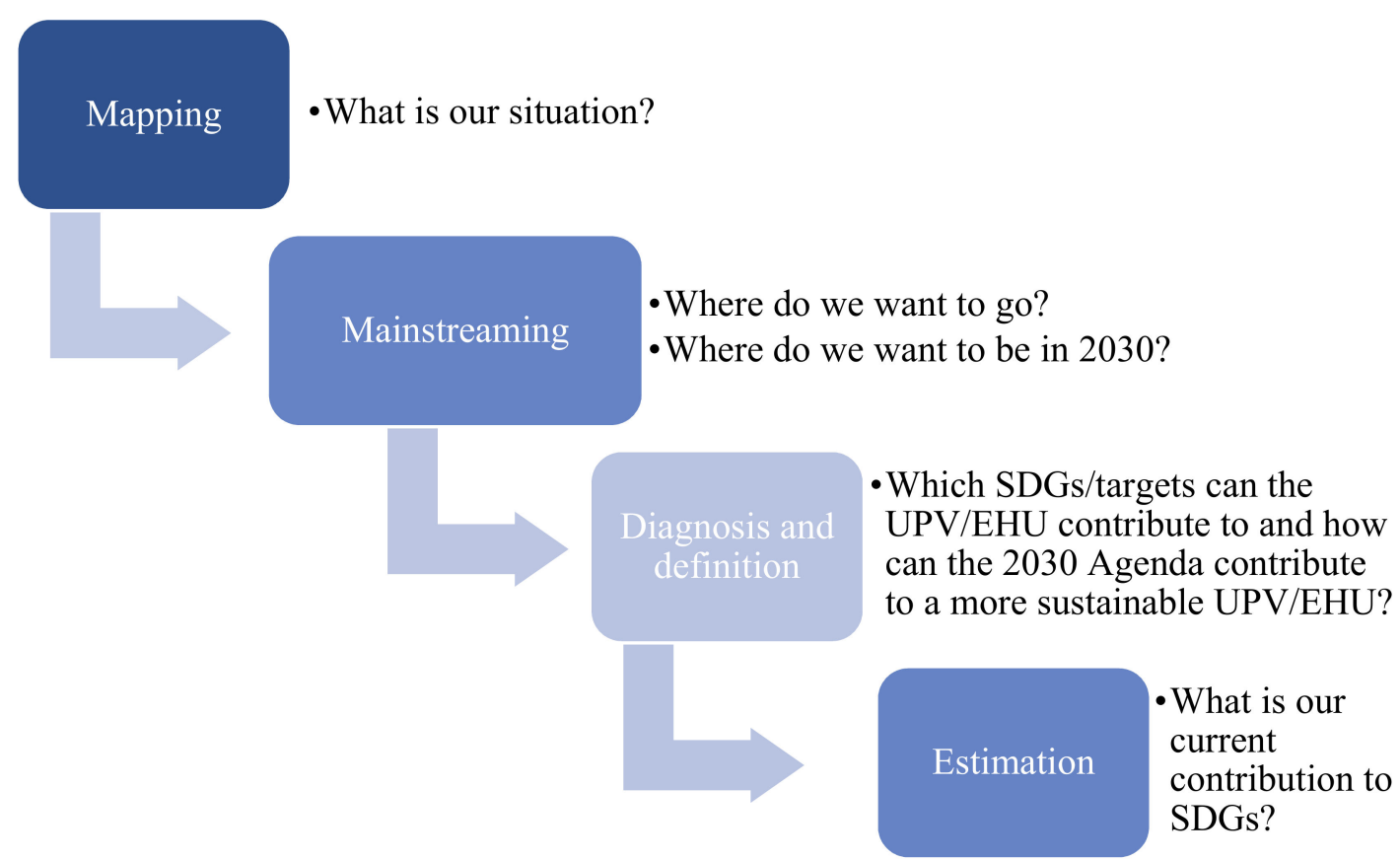

Figure 1. Process sequence set up to integrate the devise the 2030 agenda in the University of the Basque Country (UPV/EHU).

We found out that the people who teach, conduct research, study and work at the UPV/EHU address these SDGs and challenges and pursue solutions daily for sustainable development in their classrooms, in their labs, in their learning environments and in their management roles. Some of them did so in the framework of existing programs or projects, which were analysed and listed in this first step. Some of them are described below.

- Campus Bizia Lab. This is an initiative derived from the Erasmus Project University Educators for Sustainable Development, in which academic staff, students and services staff design and execute projects in order to reduce the environmental impact of our campuses. More info: https://www.ehu.eus/es/web/iraunkortasuna/campus-bizialab

- Akademe. This is a programme to empower young women to lead research teams and departments or other units. https://www.ehu.eus/es/web/akademe

- Ocean $i^{3}$ Project. This is an educational innovation project based on Research Based Learning methodologies focused on the "oceans plastic pollution" challenge. Its mission is to contribute to reducing pollution on the Basque-Aquitaine cross-border coast. https://euskampus.eus/en/programmes-en/euskampus-bordeaux/oceani3? set_language=en

- Gaztenpatia. A programme that promotes empathy among students by collaborating in the Euskal Fondoa (Association of local Basque cooperating entities) projects in Central America and the Sahara. https:/ / www.ehu.eus/es/web / oficop/gaztenpatia

The UPV / EHU Strategic Plan 2018-2021, the basis of university policy for that period, took up the global, interconnected and scalable definition of the concept of sustainability [27]. Goals were thus defined, such as turning the university into an institution fostering sustainable development, inclusion and social commitment (Driver: Relations with society) and encouraging students to embrace university values, collaboration, equality, critical thought, creativity and social commitment, thereby assisting their comprehensive education as citizens (Driver: People). Both goals established specific mandates geared towards integration. The potential contribution of these goals and mandates was analysed as well. 


\subsection{Mainstreaming}

Not all the SDGs affect university activity in the same manner, nor can the University make the same contribution to them all. It is true, it must be said, that the internal link between the goals is a close one, that one goal must lead to another and that these connections must help us to perceive the complexity of the problems and the transdisciplinary nature and independence of their solutions. However, we considered that it was necessary to draw up a roadmap and to select the "key" SDGs for the UPV/EHU. When making this selection, we reflected on the following questions: "Where do we want to go?", "Where do we want to be in 2030?", "To which SDGs can the UPV/EHU contribute?" and "How can the 2030 Agenda contribute to a more sustainable UPV/EHU?"

We selected 12 of the 17 SDGs: 3, 4, 5, 7, 8, 9, 10,11, 12, 13, 16 and 17. Moreover, we added an extra one to our roadmap: 18 or $17+1$. A critical aspect for the UPV/EHU is the development of the Basque language (Euskera), Basque culture and plurilingual capacitation, a cultural and linguistic parameter that was not specifically laid down in the SDGs. Therefore, we included SDG18, thus embracing the initiative of the UPV/EHU United Nations Educational, Scientific and Cultural Organization (UNESCO) Chair of World Linguistic Heritage [30].

The next step was how to deploy the SDGs in university activities in a global effective manner to overcome excessively isolated and fragmented visions and working methods; in other words, how to perform the mainstreaming of the strategies and our internal policies towards sustainable development.

We proposed the concentric logic depicted in Figure 2. The principal aim of much of university activity is SDG4, "Ensure inclusive and quality education for all and promote lifelong learning", as this highlights all the teaching-learning processes in their broadest and most comprehensive version. This matrix includes the expression of: SDG8, "Decent work and economic growth" striving for employability and the contribution university education makes to sustainable economic development, of SDG16, "Peace, justice and strong institutions" covering every aspect of education for human rights as an essential component of curricular logic, and SDG 17, "Partnerships for the goals" incorporating the entire spectrum of cooperation for development, commitment and social transfer, alongside SDG 18, "Cultural and linguistic diversity".

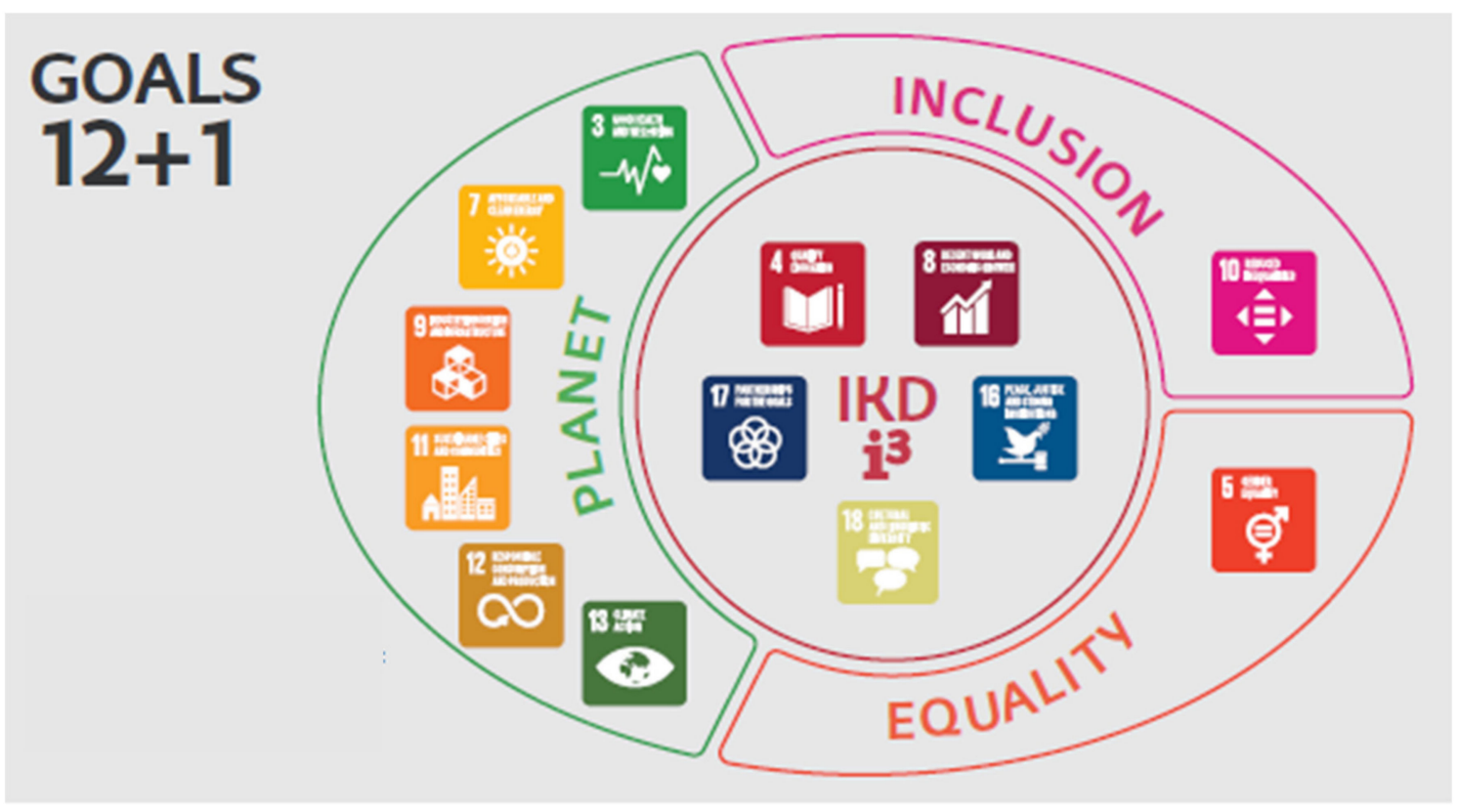

Figure 2. Diagram of concentric circles: integration, transversality and precision. Source: UPV/EHU [28]. 
Three sectoral plans were deployed alongside this core, which chiefly affects university education processes: the gender equality plan (Equality Campus), the inclusion plan (Inclusion Campus) and a health and environmental management plan (Planet Campus).

- Equality Campus, which centres on SDG5 "Gender equality", was set up based on the University's experiences in terms of equality policies for men and women, however it comes up against fresh challenges. As a priority, it attempts to make gender perspective and feminist theory part of the teaching environment and of final-year undergraduate and master projects. One of the new elements is the emphasis placed on the early augmentation of scientific and technological vocations, particularly in the case of women. Moreover, the struggle against gender violence, sexist conduct and gender-based discriminatory attitudes in the university environment, by implementing and promulgating the UPV/EHU Protocol against gender violence.

- Inclusion Campus contributes to SDG10 "Reduced inequalities", by underlining the reduction of inequality. On the same terms as the previously mentioned case, this was pieced together on the basis of the two earlier inclusion plans. Even so, the very concept of inclusion has been widened here and includes, as before, the groups of people with disabilities, but also other groups that have been variously catered for such as prisoners, refugees and people in a situation of economic vulnerability.

- Planet Campus covers SDG3 “Good health and well-being”, SDG7 "Affordable and clean energy", SDG9 "Industry, innovation and infrastructure", SDG11 "Sustainable cities and communities", SDG12 "Responsible consumption and production" and SDG13 "Climate action". This plan sets out to bring together all the environmental policies deployed by the University in the last few years. It will be performed via the pragmatic environmental management drivers: energy, water, waste, town planning and infrastructure, health and welfare, transport and mobility, responsible purchases and consumption and climate change.

Apart from these plans, the UPV/EHU's own educational model Ikaskuntza Kooperatibo eta Dinamikoa (IKD) [31] underwent a review in this process to bring it into line with modern pedagogical trends, the renewed European Union Agenda for Higher Education [32] and its funding programmes (Erasmus+, Marie Sklodowska-Curie Actions, Horizon 2020 and European Structural and Investment Funds (ESIF) as well as the 2030 Agenda.

The outcome was IKD i ("i to the power of three": learning ("ikaskuntza" in Basque) x research ("ikerkuntza") x sustainability ("iraunkortasuna"), which means multiplying learning by research and by sustainability, namely exponential growth of each of these terms, paving the way for processes and products hitherto unknown.

With more than 290 research teams operational the UPV/EHU has the greatest research capacity in the Basque Country, in all knowledge areas. It has a high environment transfer capacity and competitive master's and doctorate programmes; there must be more fluid links between research and transfer capital and degree qualifications, especially undergraduate and master's degrees, due to the fact that we believe that deepening (intensifying/expanding/broadening) complex competences would result in adding knowledge of how to conduct research, inquiry and innovation to basic desirable competences for every student. There is no better opportunity for carrying out this task than the UPV/EHU and this has already been borne out by a number of specific experiences.

Sustainability is the third component of this exponential formula. We are convinced that learning capacity multiplied by research capacity is not adequate if the planet's greatest challenges are not targeted, and at this point in time its greatest challenges are the SDGs. Thus, these ideas and these areas of tension must be part of the mindsets and actions of all those who take part in the university community. They must design courses, subjects, programmes, practicums, labs, mobility and conversations with the social, economic, environmental and cultural environment. In parallel, the UPV/EHU Catalogue of Transversal Competences was published, which establishes eight competences that are common to all UPV/EHU degree qualifications [33]. 
IKD $\mathrm{i}^{3}$ is the medium/long-term response that the UPV/EHU wishes to implement within its own educational model. Among other aspects, work will focus on:

- Institutional incorporation of the UPV/EHU's catalogue of common transversal competences, together with programmes for adjustment, planning, curricular upgrades at the levels of undergraduate, master, doctorate and continuous training.

- Updating teaching guides for undergraduate and master subjects, providing visibility for $\mathrm{i}^{3}$ action.

- Addition to already established active methodologies, inquiry-based learning and research-based learning.

- Reinforcing and extending programmes or initiatives that create experiences with a high-training impact on students, individual or group experiences, self-managed volunteer experiences or development cooperation work.

- Exploring the possibilities of more extensive curricular niches: sequence of voluntary work/business internship/practicum + final-year undergraduate project/final-year master project/doctoral theses, with the aim of making significant contributions from the perspective of the SDGs.

- Joint final-year undergraduate projects or final-year master projects based on one of the university's common challenges.

- Experimenting with the idea of co-management processes for final-year undergraduate projects and final-year master projects with research teams, external companies and bodies (by way of practicum tutorials), to give students first-hand knowledge of these real contexts and enter into teaching-learning relationships with external agents (mentoring).

- Upgrading and promoting, at a congress, final-year undergraduate projects and finalyear master projects that have made a wholly new or particularly advantageous contribution to a certain problem or challenge, with sustainability as a driving factor.

- Acknowledging structured $\mathrm{IKDi}^{3}$ teaching teams, meaning teams teaching subjects, areas or modules with an innovative practice that produce tried and trusted results in terms of teaching, and also in terms of what students learn (success rates and satisfaction with teaching methodology).

It is highly probable that the multiplicator capacity of the blending of research, learning and sustainability will guide the materialisation of EHUagenda 2030.

As shown in Figure 3, the EHUagenda 2030 for sustainable development has a concentric logic to permit a common interdependent relationship, particularly in the teachinglearning processes. This will also be an autonomous feature of the gender equality plan, the inclusion plan and the health and environmental management plan, as their work and services will concentrate on these areas.

This concentric logic that underpins the EHUagenda 2030 is integrational, transversal, precise and specific. The development of this logic not only called for a mapping process to be implemented and ascertaining what is already being carried out, but also required more meshed and interrelated ways of doing so. It is also transversal because, although four "structures" may be observed, the courses of action demonstrate some solid intersections. Finally, it is precise and specific because it functions with quantifiable hurdles described in detail on the agenda's indicator panel (see next step).

Although EHUagenda 2030 works on a medium/long-term outlook ending in 2030, a formative 2019-2025 period is contemplated for appraisal of achievements, and milestones will be set for 2025-2030. Furthermore, a tracking report will be produced annually to enable corrections and adaptations to be made to help achieve the targets.

\subsection{Diagnosis and Definition of Indicators}

The next step was to analyse and select the benchmark SDGs, targets and indicators for the UPV/EHU. We reflected on the following questions: "To which SDGs/targets can the UPV/EHU contribute, and how can the 2030 Agenda contribute to a more sustainable UPV/EHU?". 


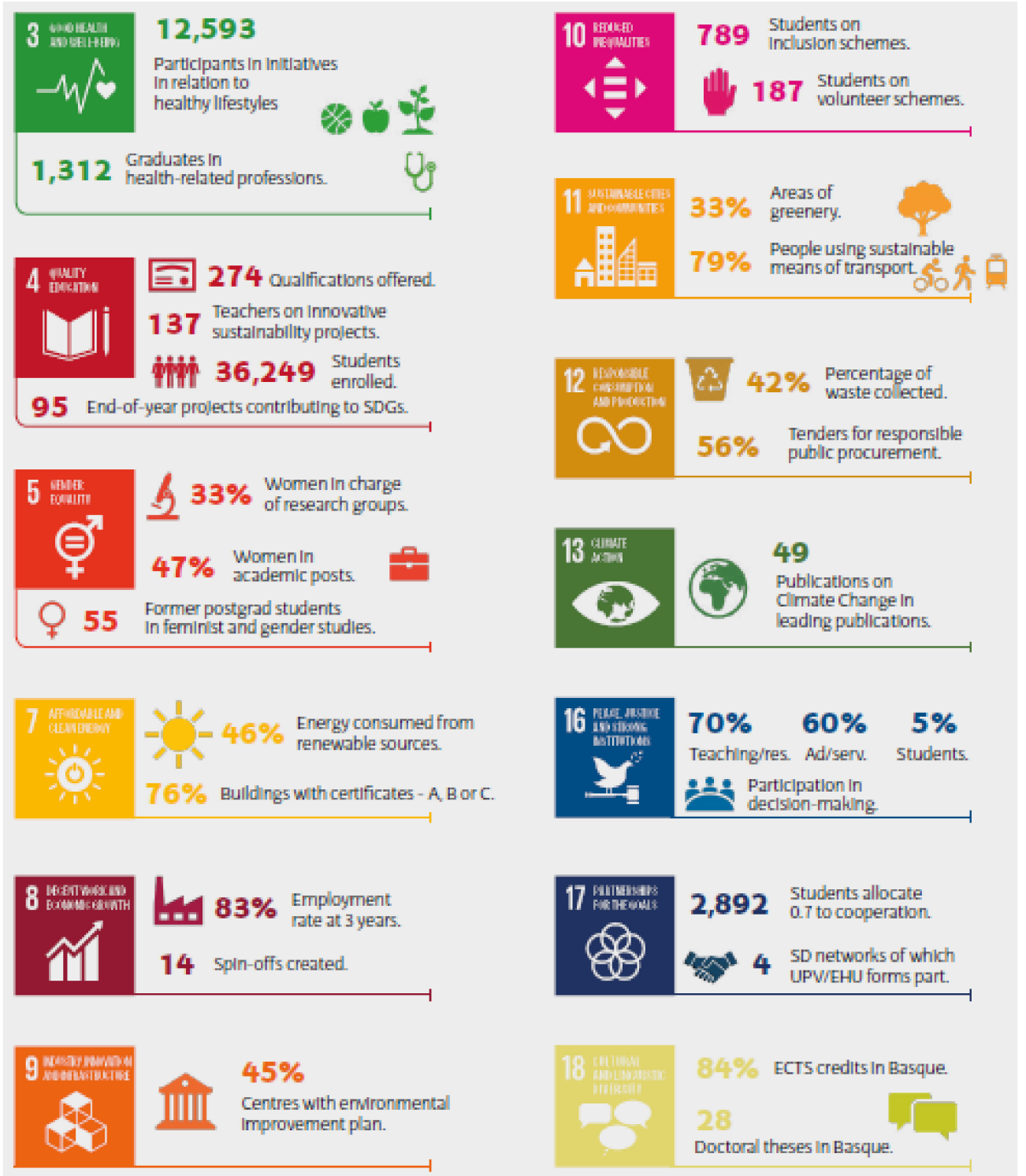

Figure 3. Summary of the results of some of the sustainable development indicators for the academic year 2017/18.Source: UPV/EHU [29].

A considerable number of the tasks were carried out to determine the aims and the conclusions were contrasted with several agents. Given that the UPV/EHU is already taking action as per its ongoing plans, the reflection group concluded that the UPV/EHU can make a contribution to 13 SDGs (12 of the 17 SDGs and SDG18) through 35 targets. Targets were not considered literally, but have been adopted as the benchmark targets in view of their scope and objectives. They are detailed in Table 1.

After this, a panel of 58 indicators was defined to carry out a monitoring process in accordance with the reality of the university [20]. The panel is presented in Table 2. 
Table 1. United Nations Sustainable Development Goals (SDGs) and targets concerning the UPV/EHU.

\begin{tabular}{|c|c|c|}
\hline SDG & Number of Targets & Targets \\
\hline \multirow{3}{*}{ 3-Good health and well-being } & \multirow{3}{*}{3} & 3.4 \\
\hline & & 3.5 \\
\hline & & 3.c \\
\hline \multirow{5}{*}{ 4-Quality education } & \multirow{5}{*}{5} & 4.3 \\
\hline & & 4.4 \\
\hline & & 4.5 \\
\hline & & 4.7 \\
\hline & & 4.a \\
\hline \multirow{5}{*}{ 5-Gender equality } & \multirow{5}{*}{5} & 5.1 \\
\hline & & 5.2 \\
\hline & & 5.4 \\
\hline & & 5.5 \\
\hline & & 5.c \\
\hline \multirow{2}{*}{ 7-Affordable and clean energy } & \multirow{2}{*}{2} & 7.2 \\
\hline & & 7.3 \\
\hline \multirow{3}{*}{ 8-Decent work and economic growth } & \multirow{3}{*}{3} & 8.3 \\
\hline & & 8.5 \\
\hline & & 8.8 \\
\hline \multirow{2}{*}{ 9-Industry, innovation and infrastructure } & \multirow{2}{*}{2} & 9.4 \\
\hline & & 9.5 \\
\hline \multirow{2}{*}{ 10-Reduced inequalities } & \multirow{2}{*}{2} & 10.2 \\
\hline & & 10.3 \\
\hline \multirow{2}{*}{ 11-Sustainable cities and communities } & \multirow{2}{*}{2} & 11.2 \\
\hline & & 11.7 \\
\hline \multirow{4}{*}{ 12-Responsible production and consumption } & \multirow{4}{*}{4} & 12.3 \\
\hline & & 12.4 \\
\hline & & 12.5 \\
\hline & & 12.7 \\
\hline 13-Climate action & 1 & 13.3 \\
\hline \multirow{3}{*}{ 16-Peace, justice and strong institutions } & \multirow{3}{*}{3} & 16.6 \\
\hline & & 16.7 \\
\hline & & 16.a \\
\hline \multirow{3}{*}{ 17-Partnerships for the goals } & \multirow{3}{*}{3} & 17.2 \\
\hline & & 17.6 \\
\hline & & 17.17 \\
\hline
\end{tabular}


Table 2. Panel of indicators of the UPV/EHU. Source: UPV/EHU [29].

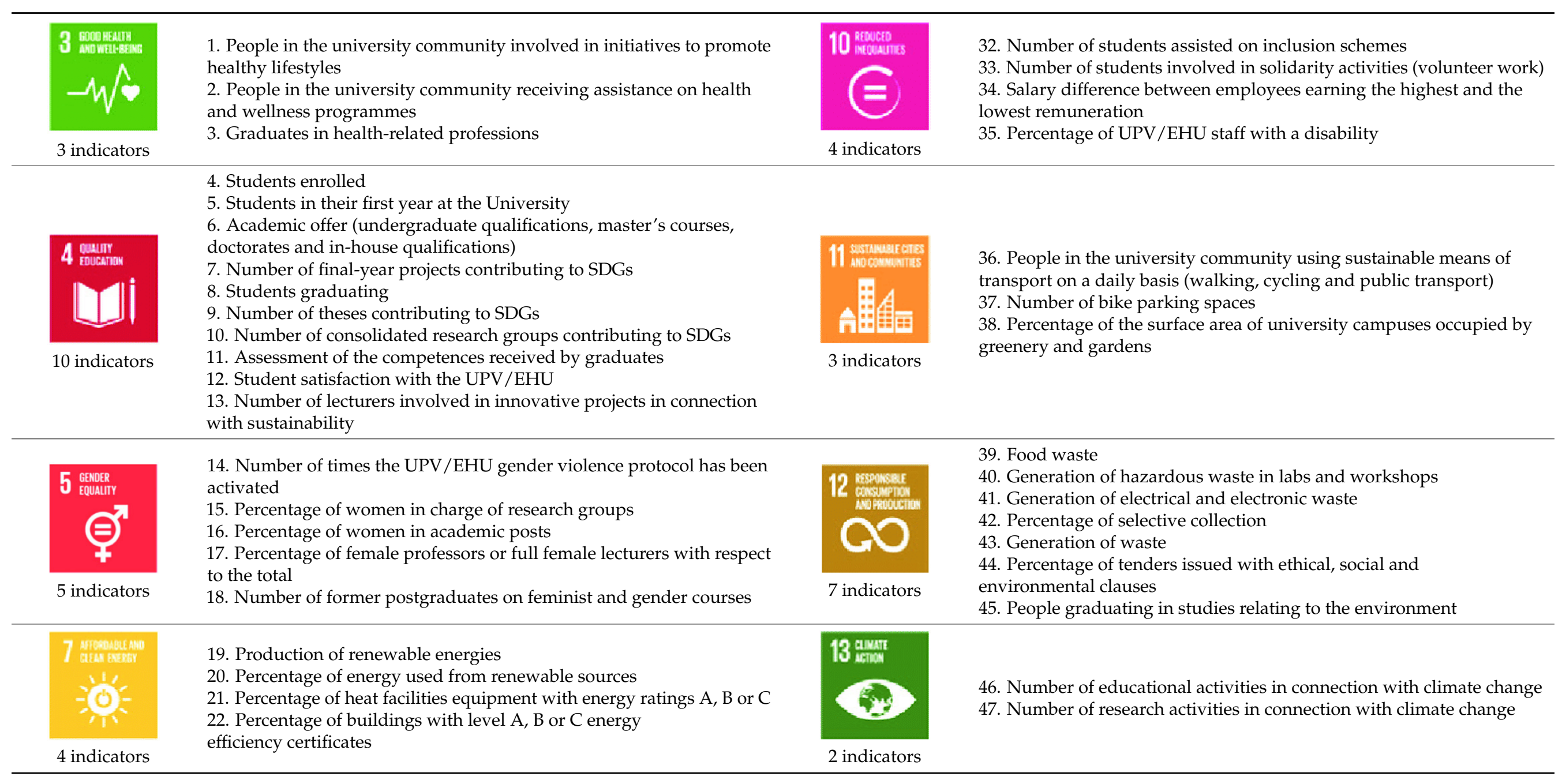


Table 2. Cont.

\begin{tabular}{|c|c|c|c|}
\hline 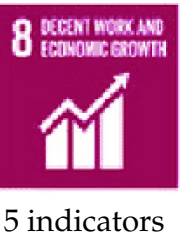 & $\begin{array}{l}\text { 23. Number of spin-offs created } \\
\text { 24. Number of high-qualification jobs in companies created by } \\
\text { the University } \\
\text { 25. Rate of employment of former students at three years } \\
\text { 26. Time elapsing up to the first job } \\
\text { 27. Percentage of UPV/EHU staff with permanent contract }\end{array}$ & $16 \frac{\cos u \sin x}{2 \text { indicators }}$ & $\begin{array}{l}\text { 48. UPV/EHU transparency index } \\
\text { 49. Accountability } \\
\text { 50. Participation by the university community in decision-making } \\
\text { 51. Percentage of UPV/EHU staff providing special services in local, } \\
\text { regional, national or European governments }\end{array}$ \\
\hline 4 indicators & $\begin{array}{l}\text { 28. GHG inventory } \\
\text { 29. Percentage of teaching centres with a plan to improve } \\
\text { environmental performance } \\
\text { 30. Number of events certified with an environmental seal } \\
\text { 31. Number of patents or licences operated that contribute to SDGs }\end{array}$ & 5 indicators & $\begin{array}{l}\text { 52. Number of student volunteers offering } 0.7 \% \text { of their enrolment fee to } \\
\text { be used on university development cooperation projects } \\
\text { 53. Number of development cooperation projects } \\
54 \text {. Number of students involved in development cooperation projects } \\
\text { 55. Number of collective agreements with public authorities and } \\
\text { social bodies } \\
\text { 56. UPV/EHU participation in networks in relation to } \\
\text { sustainable development }\end{array}$ \\
\hline & & 2 indicators & $\begin{array}{l}\text { 57. Percentage of European Credit Transfer and Accumulation System } \\
\text { (ECTS) credits offers in Basque on undergraduate courses } \\
\text { 58. Number of doctoral theses in Basque }\end{array}$ \\
\hline
\end{tabular}


The panel of sustainable development indicators complements the roadmap and contributes to it as follows:

- Enhancing EHUagenda 2030. The indicator panel will serve as a basis to draw up annual follow-up reports. By 2025, the indicator panel, consolidated with the indicators taken into consideration in each sectoral plan and amalgamated with the results of the assessment of the sectoral plans, will be used as a basis to conduct an in-depth assessment of compliance with EHUagenda 2030 and to establish milestones for 2025-2030.

- Comparability and benchmarking compared to other universities. The indicator panel can be used to juxtapose data with other universities, on the condition that they use a similar methodology. In the same way, the possibility is considered for using the panel as a basis for mainstream rankings in order to draw comparisons with universities worldwide and pinpoint areas for improvement.

- $\quad$ Socialising and publicising the SDGs among the university community. When the panel has been made known to lecturers, the definition of the indicators will encourage and incentivise the inclusion of specific aspects of SDGs in syllabuses. Indicators relating to the UPV / EHU internal aspects as an organisation will encourage administrative and services staff to determine and prioritise areas of improvement within the organization. Information presented based on the SDGs will incentivize and motivate students to contribute in other aspects.

- Disseminating information will make the Basque society aware of the SDGs, which are increasingly in the general domain.

- Finally, in general, but especially with regard to indicators relating to the organisation, the information published will include a certain amount of traction to specify the contribution that organisation can make to the SDGs with companies and/or contractors offering services to the UPV/EHU, and other administrations with which the UPV/EHU works.

The UPV /EHU Panel of Sustainable Development document [20] details the work methodology used to define it, the objectives and utilities, the description of the methodological sequence and the results of this task: the mapping of the goals and targets adopted, the indicator panel and the technical data sheets for each indicator. This panel has been recently used by the Sustainable Development Solutions Network delegation in Spain to prepare the guide for all Spanish Universities [34].

The methodological data sheet for each of the indicators specifies the definition, unit, source, regularity of the calculation, calculation methodology, SDG concerned and United Nations target or targets concerned. An example is shown in Table 3.

\subsection{Estimating the Indicators and Establishing the Baseline}

Finally, we considered that the UPV/EHU baseline with respect to achieving SDGs needed to be marked out, in addition to the EHUagenda 2030 for sustainable development and its indicator panel. Thus, the first measurement was made in order to answer to the question "What is our current contribution to SDGs?".

We therefore availed ourselves of data for the academic year 2017/18 as the baseline to monitor information and assess achievement level. Figure 3 provides a summary of the panel of indicators defined in coherence with the role of the UPV / EHU in the SDGs and the data for the academic year $2017 / 18$.

The implementation of this EHUagenda 2030 for sustainable development has been a major challenge in itself, though. Even though the UPV/EHU was not embarking on this from scratch, as it had already made a contribution to the SDGs, it has involved an important rethink of our activity to focus it proactively and operationally on specific targets. 
Table 3. Summary of the results of some of the indicators for sustainable development for the academic year $2017 / 18$.

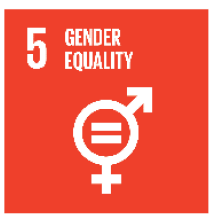

17. Percentage of female professors or female full lecturers with respect to the total

Definition

Percentage of female professors or female full lecturers with respect to the total number of female and male professors or full lecturers during the academic year

\begin{tabular}{crcc}
\hline Unit & $\%$ & Broken down into sexes & Not applicable \\
\hline Source & Equality Department & Regularity of the calculation & Annual \\
\hline Calculation methodology & $\begin{array}{c}\text { Number of female professors or female full lecturers at the end of the academic year/Number of } \\
\text { female and male professors or full lecturers at the end of the academic year }\end{array}$ \\
\hline SDG concerned & 5. Achieve gender equality and empower all women and girls \\
\hline $\begin{array}{c}\text { United Nations Target(s) } \\
\text { concerned }\end{array}$ & $\begin{array}{c}\text { 5.1 End all forms of discrimination against all women and girls everywhere } \\
\text { 5.5 Ensure women's full and effective participation and equal opportunities for leadership at all } \\
\text { levels of decision-making in political, economic and public life }\end{array}$ \\
\hline
\end{tabular}

\subsection{Discussion}

The study carried out by Paletta et al. [25] highlighted that universities are complex, polycentric and multi-stakeholder organizations, for which sustainability can represent an opportunity to promote new institutional governance mechanisms, coherently orienting internal decision-making processes, allocation of resources and the incentive system for teaching and research. Putting these ideas into practice can lead to tensions and dysfunctions that could make real change difficult. Thus, it is necessary to undertake medium-long term processes of strategic change and with the participation and support of different groups and interests. The difficulty in our case is to 'naturalize' or normalize these changes so that the university community assumes that the UN 2030 Agenda and SDGs are not a temporary fashion, but rather a new ethic for our planet and our society. It is an ideological "disruption" that has being further exacerbated by the emergence of the COVID-19 pandemic since March 2020. Changing the operating culture and mission of higher education institutions putting them at the service of the common global challenges involves changes from the micro level to the macro, and destabilize many comfort zones.

Another opportunity is the operational definition and measurement of indicators that respond to the strategies proposed by each university to carry out its own development and appropriate UN 2030 Agenda. In this regard, the first step would be to ask ourselves what kind of indicators, why these indicators and what do we want these indicators for. In our case, the answers to these three questions were conditioned by our own reading of sustainability, that is, what does sustainability mean for the University of the Basque Country, which coincides with a great extent with Paletta et al. conclusions [25]. The University of the Basque Country is a young public institution (40 years of history), with a strong identification with its environment and with its hallmarks: the Basque language and the Basque culture. Its strategic commitment to the SDGs is not by chance, since these goals include many of the missions that the Basque society has entrusted to our institution. Our indicators and their monitorization become tools at the service of the EHUagenda 2030 itself and, at the same time, produces tangible results locally as well as equally tangible results to the specific targets of the international agenda. With this panel of indicators, we do not renounce reporting our achievements and contributions to international standardized systems. However, we are convinced that in addition to these international standardized systems, higher education institutions need their own indicators, which are adapted to the context and the needs of each of these. 
Indicators, if presented in systematic and clear terms, are not only the measurement of an outcome but also signals of the direction of change and, in addition, catalysts for achievement. In this special issue on "Evaluation and indicators for sustainability: governance and resilience?", we would dare to venture that, indeed, the monitoring of good indicators, of true indicators, are an effective way, along with others, to join forces towards the transformation of higher education in the direction of this new, and inevitable, philosophy that guides UN 2030 Agenda and SDGs. Our experience is that if the university endorses its indicators, it values them and the university community strives to obtain good results. As a result, they lead to the organization as a whole towards a change in culture. In contrast, if indicators are not endorsed and valued, the university turns the indicators into an additional administrative burden, which obviously has the opposite effect of the one desired. In short, from our point of view, universities, beyond being monitored and measured by external agencies (international rankings, quality assurance agencies and so on), must take control of their destiny and decide what they want to contribute, considering their situation and real possibilities.

Finally, some remarks should be made about the limitations of this study. As mentioned before, this is a case study and, thus, it describes a specific and space-time localized process. These is not a directly portable process or generalizable indicators and data that can lead to more robust syntheses. In order to advance the knowledge of integrated approaches to the development of sustainability at the university level, an increase in the number of real institutional experiences and their rigorous analysis would be necessary. This would enable the configuration of a minimum corpus of scientific knowledge. At this stage, qualitative research is essential and case studies are its best expression. A good number of local cases would give rise to studies of greater magnitude and comparability that allow us to observe common factors and trends. The second limitation is the short lifetime of the experience presented, which is only two years old. We pointed out that a strategic project like this needs a time perspective in the medium-long term. We have already carried out two outcome measures and progress was observed in some of the indicators, but there are also setbacks caused by the effects of the pandemic. Resilience is the concept that should guide many of the forecasts we make in the coming academic years.

\section{Conclusions}

Universities, whose mission is to create and disseminate knowledge, have a vital role to play in addressing the planet's greatest challenges and achieving the SDGs of the 2030 Agenda for sustainable development. They have realized the importance of integrating the 2030 Agenda and SDGs into their strategies, both for the benefit to society and for the apparent benefit for the institution itself. However, operational deployment from a general commitment to specific strategies compels universities to ponder the scope and content of SDGs, targets and indicators in context. This task has proven to be difficult.

The University of the Basque Country (UPV/EHU) was determined to turn the university into an institution fostering sustainable development, inclusion and social commitment and to do so from a solid strategy. Thus, in 2017 it initiated a reflection process that concluded in 2019 with the approval of the EHUagenda 2030 for sustainable development and an indicator panel.

In this paper, a case of incorporation of the SGDs into a university as a whole has been presented: the transformations that this strategic decision caused in terms of (1) rethinking the educational model, (2) reconstructing previous sectoral plans, (3) aligning efforts in a shared direction, (4) planning and redesigning considering the contributions of stakeholders and, (5) proposing a transparent and operational method of control and accountability. The result is the EHUagenda 2030, a roadmap for the period 2019-2025 seeking to bring the work of the University in line with the planet's greatest challenges and to move towards a verifiable and pragmatic contribution. It describes the UPV/EHU's contribution to 12 of the 17 SDGs, with the addition of its own commitment to linguistic and cultural diversity (SDG $17+1$ ) and the sectoral plans this comprises: Equality Campus, 
Inclusion Campus and Planet Campus. It also describes the refocus of its education model IKD $\mathrm{i}^{3} ; \mathrm{i}^{3}$ stands for ikaskuntza $\mathrm{x}$ ikerketa $\mathrm{x}$ iraunkortasuna in Basque (learning $\mathrm{x}$ research $\mathrm{x}$ sustainability). Additionally, it includes the panel of indicators for sustainable development, which addresses the technical aspects of monitoring SDGs and the selected targets. It also incorporates the UPV/EHU's current baseline and for the 2017/18 academic year.

The methodology used in this process (mapping; mainstreaming; diagnosis and definition and, finally, estimation) and presented in this paper could be replicated in other universities yet to embark on this integration. The steps and findings presented here can also be applied to other organizations.

Author Contributions: The contribution of all authors has been balanced in all phases of the development of this study. All authors have read and agreed to the published version of the manuscript.

Funding: This work was supported by the Basque Government under the through programme contracts D38 "Desarrollar la 1a Agenda de Desarrollo Sostenible de la UPV/EHU 2019-2024 para seguir avanzando en la gestión universitaria de la sostenibilidad medio-ambiental" and D17 "Afianzar el uso de metodologías docentes activas a través de la estrategia de $\mathrm{i}^{3}$ y el desarrollo del Aprendizaje basado en la indagación.".

Institutional Review Board Statement: Ethical review and approval were waived for this study, due to not involving personally identifiable nor sensitive data.

Informed Consent Statement: Not applicable.

Data Availability Statement: Data is contained within the article. Additional data are available on request from the corresponding author.

Acknowledgments: The authors would like to thank the Public Society for Environmental Management of the Basque Government (IHOBE) for its support and assistance with the project of the panel of indicators of sustainable development, as well as all the collaborators involved in the process of reflection.

Conflicts of Interest: The authors declare no conflict of interest.

$\begin{array}{ll}\text { Abbreviations } \\ \text { AASHE } & \text { Association for the Advanced Sustainability in Higher Education } \\ \text { ECTS } & \text { European Credit Transfer and Accumulation System } \\ \text { EfSD } & \text { Education for Sustainable Development } \\ \text { ESIF } & \text { European Structural and Investment Funds } \\ \text { GHESP } & \text { Global Higher Education for Sustainability Partnership } \\ \text { HESD } & \text { Higher Education and Research for Sustainable Development } \\ \text { IKD } & \text { Ikaskuntza Kooperatibo eta Dinamikoa (Cooperative and Dynamic Learning) } \\ \text { i }^{3} & \text { ikaskuntza x ikerkuntza x iraunkortasuna (learning x research x sustainability) } \\ \text { ISCN } & \text { International Sustainable Campus Network } \\ \text { MDG } & \text { Millennium Development Goals } \\ \text { REDS } & \text { Red Española para el Desarrollo Sostenible (Spanish Network for Sustainable } \\ \text { SDG } & \text { Development) } \\ \text { SDSN } & \text { Sustainable Development Goals } \\ \text { SEPN } & \text { Sustainable Development Solutions Network } \\ \text { UE4SD } & \text { Sustainability and Education Policy Network } \\ \text { ULSF } & \text { University Educators for Sustainable Development } \\ \text { UN } & \text { University Leaders for a Sustainable Future } \\ \text { UPV/EHU } & \text { United Nations } \\ \text { EEES } & \text { Country) } \\ & \text { European Higher Education System }\end{array}$




\section{References}

1. United Nations. Transforming Our World: The 2030 Agenda for Sustainable Development. UN General Assembly, 21st October 2015 A/RES/70/1. 2015. Available online: www.refworld.org/docid/57b6e3e44.html (accessed on 30 March 2020).

2. Roberts, L.; Ajai-Ajagbe, P. Higher Education and the Millennium Development Goals: Where Are We Coming From, and Where Are We Going? The Association of Commonwealth Universities. 2013. Available online: http://www.acup.cat/sites/default/ files/beyond-2015-background-report-final_1.pdf (accessed on 10 May 2020).

3. Sustainable Development Solutions Network Australia/Pacific. Getting Started with the SDGs in Universities: A Guide for Universities, Higher Education Institutions, and the Academic Sector. Australia, New Zealand and Pacific Edition. Sustainable Development Solutions Network-Australia/Pacific, Melbourne. 2017. Available online: http://ap-unsdsn.org/regionalinitiatives/universities-sdgs/university-sdg-guide (accessed on 30 March 2020).

4. Association of Commonwealth Universities; Agence Universitaire de la Francophonie; International Association of Universities. Higher Education's Essential Contribution to the SDGs. 2019. Available online: https://www.iau-aiu.net/IMG/pdf/highereducation_s-essential-contribution-to-the-sdgs.pdf (accessed on 10 May 2020).

5. Tilbury, D. Another World is Desirable: Transforming Higher Education for Sustainability. The Sustainable University: Process and Prospects; Sterling, S., Maxey, L., Luna, H., Eds.; Earthscan/Routledge: London, UK, 2013; ISBN 978-0-415-62774-0.

6. UNESCO (2017) Education for Sustainable Development Goals: Learning Objectives. Available online: https://unesdoc.unesco. org/ark:/48223/pf0000247444 (accessed on 30 March 2020).

7. Owen, R.; Macnaghten, P.; Stilgoe, J. Responsible research and innovation: From science in society to science for society, with society. Sci. Public Policy 2012, 39, 751-760. [CrossRef]

8. Hoover, E.; Harder, M.K. What lies beneath the surface? The hidden complexities of organizational change for sustainability in higher education. J. Clean. Prod. 2015, 106, 175-188. [CrossRef]

9. Niedlich, S.; Bauer, M.; Doneliene, M.; Jaeger, L.; Rieckmann, M.; Bormann, I. Assessment of sustainability governance in higher education institutions-A systemic tool using a governance equalizer. Sustainability 2020, 12, 1816. [CrossRef]

10. Global University Network for Innovation. Sustainable Development Goals: Actors and Implementation A Report from the International Conference. 2018. Available online: http://www.acup.cat/sites/default/files/2018-06/GUNi_SDGs_Report_0.pdf (accessed on 10 May 2020).

11. Sustainable Development Goals Acord. The University and College's Sectors Collective Response to the Global Goals 2020. Available online: https:/ / www.sdgaccord.org/case-studies (accessed on 15 May 2020).

12. Red Española para el Desarrollo Sostenible-REDS. Implementando la Agenda 2030 en la Universidad. Casos Inspiradores. 2020. Available online: https:/ /reds-sdsn.es/wp-content/uploads/2020/05/Dosier-REDS_Casos-ODS-Univ-2020_web.pdf (accessed on 15 May 2020).

13. International Sustainable Campus Network. Sustainable Campus Best Practices from ISCN and Gulf Universities. 2018. Available online: https:/ /international-sustainable-campus-network.org/iscn-sustainable-campus-best-practices (accessed on 30 March 2020).

14. Universitas Indonesia. UI GreenMetric World University Ranking. 2020. Available online: https://greenmetric.ui.ac.id (accessed on 15 May 2020).

15. Times Higher Education. THE University Impact Rankings 2019: Methodology. 2020. Available online: https://www. timeshighereducation.com/university-impact-rankings-2019-methodology (accessed on 15 May 2020).

16. Menon, S.; Suresh, M. Synergizing education, research, campus operations and community engagement towards sustainability in higher education: A literature review. Int. J. Sustain. High. Educ. 2020, 21, 1015-1051. [CrossRef]

17. Waltner, E.-M.; Rieß, W.; Brock, A. Development of an ESD Indicator for teacher training and the national monitoring for ESD implementation in Germany. Sustainability 2018, 10, 2508. [CrossRef]

18. Avelar, A.B.; Silva-Oliveira, K.D.; Silva Pereira, R. Education for advancing the implementation of the sustainable development goals: A systematic approach. Int. J. Manag. Educ. 2019, 17, 100322. [CrossRef]

19. Leal Filho, W.; Wu YC, J.; Brandli, L.L.; Avila, L.V.; Azeiteiro, U.M.; Caeiro, S.; Madruga, L.R.D.R.G. Identifying and overcoming obstacles to the implementation of sustainable development at universities. J. Integr. Environ. Sci. 2017, 14, 93-108. [CrossRef]

20. Lozano, R.; Ceulemans, K.; Alonso-Almeida, M.; Huisingh, D.; Lozano, F.J.; Waas, T.; Lambrechts, W.; Lukman, R.; Hugé, J. A review of commitment and implementation of sustainable development in higher education: Results from a worldwide survey. J. Clean. Prod. 2015, 108, 1-18. [CrossRef]

21. Leal Filho, W.; Shiel, C.; Paço, A.; Mifsud, M.; Veiga Ávila, L.; Londero Brandli, L.; Molthan-Hill, P.; Pace, P.; Azeiteiro, U.M.; Ruiz Vargas, V.; et al. Sustainable development goals and sustainability teaching at universities: Falling behind or getting ahead of the pack? J. Clean. Prod. 2019, 232, 285-294. [CrossRef]

22. Shiel, C.; Smith, N.; Cantarello, E. Aligning campus strategy with the SDGs: An institutional case study. In Universities as Living Labs for Sustainable Development; World Sustainability Series; Filho, W.L., Salvia, A.L., Pretorius, R.W., Brandli, L.L., Manolas, E., Alves, F., Azeiteiro, U., Rogers, J., Shiel, C., Paco, A.D., Eds.; Springer: Cham, Switzerland, 2020.

23. Leal Filho, W.; Pallant, E.; Enete, A.; Richter, B.; Brandli, L.L. Planning and implementing sustainability in higher education institutions: An overview of the difficulties and potentials. Int. J. Sustain. Dev. World Ecol. 2018, 25, 713-721. [CrossRef]

24. Mawonde, A.; Togo, M. Implementation of SDGs at the university of South Africa. Int. J. Sustain. High. Educ. 2019, 20, 932-950. [CrossRef] 
25. Paletta, A.; Bonoli, A. Governing the university in the perspective of the United Nations 2030 Agenda: The case of the University of Bologna. Int. J. Sustain. High. Educ. 2019, 20, 500-514. [CrossRef]

26. Mori Junior, R.; Fien, J.; Horne, R. Implementing the UN SDGs in Universities: Challenges, opportunities, and lessons learned. Sustainability 2019, 12, 129-133. [CrossRef]

27. University of the Basque Country. Plan Estratégico de la UPV/EHU 2018-2021. 2018. Available online: https:/ / www.ehu.eus / es/web/idazkaritza-nagusia/upv-ehuren-plan-estrategikoa-2018-2021 (accessed on 30 March 2020).

28. University of the Basque Country. EHU agenda for Sustainable Development. 2019. Available online: https://www.ehu. eus/documents/4736101/11938005/EHUAgenda-2030-ENG.pdf/487b2c83-51e1-d0e2-dcd1-af419b2b5c26 (accessed on 30 March 2020).

29. University of the Basque Country. Panel of Indicators for Sustainable Development of the UPV/EHU. 2019. Available online: https: / / www.ehu.eus/documents /4736101/11938005/EHUagenda2030-Panel-of-indicators.pdf/40e28e80-4e8b-421c-66 e7-6ec589c573d1 (accessed on 30 March 2020).

30. UNESCO Chair of World Linguistic Heritage of the University of the Basque Country. Exhibition Information Pamphlet. United Nations Agenda 2030. “17 + 1”. 2018. Available online: https://www.ehu.eus/documents/3120344/3356414/18+helb+ argumentuak_gaz.pdf/56b65d4b-6387-0c61-5f6c-44ee02d3b616 (accessed on 30 March 2020).

31. University of the Basque Country. Irakaskuntza Kooperativo eta Dinamikoa. Modelo Educativo de la UPV/EHU. 2010. Available online: https: / / www.ehu.eus/es/web/sae-helaz/ikd (accessed on 30 March 2020).

32. European Commission. Communication from the Commission to the European Parliament, the Council, the European Economic and Social Committee and the Committee of the Regions on a Renewed EU Agenda for Higher Education 2017. Available online: https: / / eur-lex.europa.eu/legal-content/EN/TXT/PDF/?uri=CELEX:52017SC0164\&from=en (accessed on 30 March 2020).

33. University of the Basque Country. Catálogo de Competencias Transversales de la UPV/EHU 2019. Available online: https: / / www.ehu.eus/documents/1432750/12757375/Cat\%C3\%A1logo+de+Competencias+trasnversales_cas.pdf (accessed on 30 March 2020).

34. Red Española para el Desarrollo Sostenible-REDS. Cómo Evaluar los ODS en las Universidades. 2020. Available online: https: / reds-sdsn.es/wp-content/uploads/2020/04/Gui\%CC\%81a-COMO-EVALUAR-ODS-2020-AAFF.pdf (accessed on 15 May 2020) 